\title{
Humeroradioulnar synostosis in a patient with lambdoid synostosis
}

\author{
T J C Edwards, E A Haan, I J Humphrey
}

\begin{abstract}
We report on a patient with humeroradioulnar synostosis and lambdoid synostosis. The case differs from three previously described cases in minor details, but the upper limb abnormalities are strikingly similar.

( $\mathcal{F}$ Med Genet 1993;30:81-2)
\end{abstract}

Cases of upper limb oligoectrosyndactyly have previously been described by Hersh et al, ${ }^{1}$ Leroy and Speeckaert, ${ }^{2}$ and Gollop and Coates. ${ }^{3}$ The cases described by these authors all exhibited bilateral upper limb deformities. In addition, two of the three cases showed mild plagiocephaly. The infant described in this article was born with a unilateral upper limb deformity that was similar to those previously described, along with plagiocephaly owing to right lambdoid craniosynostosis.

\section{Case report}

The proband was the first child of non-consanguineous parents. He was born at term after a normal pregnancy, labour, and delivery with a birth weight of $2273 \mathrm{~g}$. The mother was of Maori and the father of European extraction.

The child was referred at 7 months of age for assessment of plagiocephaly with right occipital flattening. Weight $(5.62 \mathrm{~kg})$ and head circumference $(41.5 \mathrm{~cm})$ were below the $3 \mathrm{rd}$ centile. Both upper limbs were abnormal (fig 1). On the right there was a dimple in the skin of the upper arm overlying a bony exostosis from the medial side of the midshaft of the humerus. There was no elbow joint and the forearm

Craniofacial Unit Adelaide Medical Centre for Women and Children, 72 King William Road, North Adelaide 5006, Australia.

T J C Edwards

Department of Medical Genetics, Adelaide Medical Centre for Women and Children, 72 King William Road, North Adelaide 5006,

Australia.

E A Haan

Department of Paediatrics, Royal

Darwin Hospital,

Casuarina 0810,

Australia.

I J Humphrey

Correspondence to Dr Edwards.

Received 5 February 1991 Revised version accepted 6 May 1992.

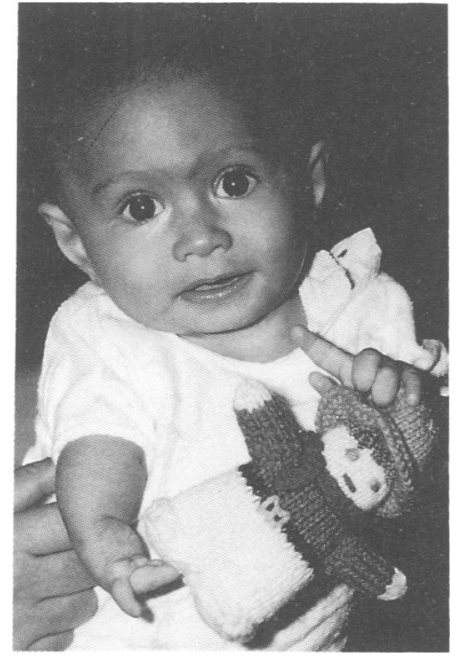

Figure 1 The child at 7 months of age. bones were absent. There were three digits, a rudimentary thumb attached by a skin tag and two other digits joined along their lengths by soft tissue (fig 2). On the left, the upper arm, elbow, forearm, and wrist were normal but the thumb was hypoplastic. The facies, the ears, anal placement, cardiovascular examination, and developmental assessment were normal.

Radiographs showed premature synostosis of the right lambdoid suture, an abnormally large anterior arch of the atlas, and fusion of the posterior elements of $\mathrm{C} 2$ and $\mathrm{C} 3$. The bases of the left fourth and fifth metacarpals were fused and all elements of the left thumb were hypoplastic. The right humerus was abnormally long with a $3 \mathrm{~cm}$ exostosis arising medially from the junction of the middle and distal thirds. The radius and ulna were absent. An ossification centre was present in the carpal region and appeared to be composed of two fused elements. There were two complete rays (metacarpals and phalanges) and a rudimentary thumb with two phalanges (fig 3). Radiographs of the lower limbs were normal.

\section{Discussion}

The three cases reported previously ${ }^{1-3}$ had almost identical limb deformities to the case presented here, the only difference being that in the case presented here the limb deformity is unilateral, whereas the previous three have shown bilateral deformity. The association of radial aplasia and craniosynostosis led us initially to entertain the diagnosis of BallerGerold syndrome. However, the very mild degree of craniosynostosis and the striking 


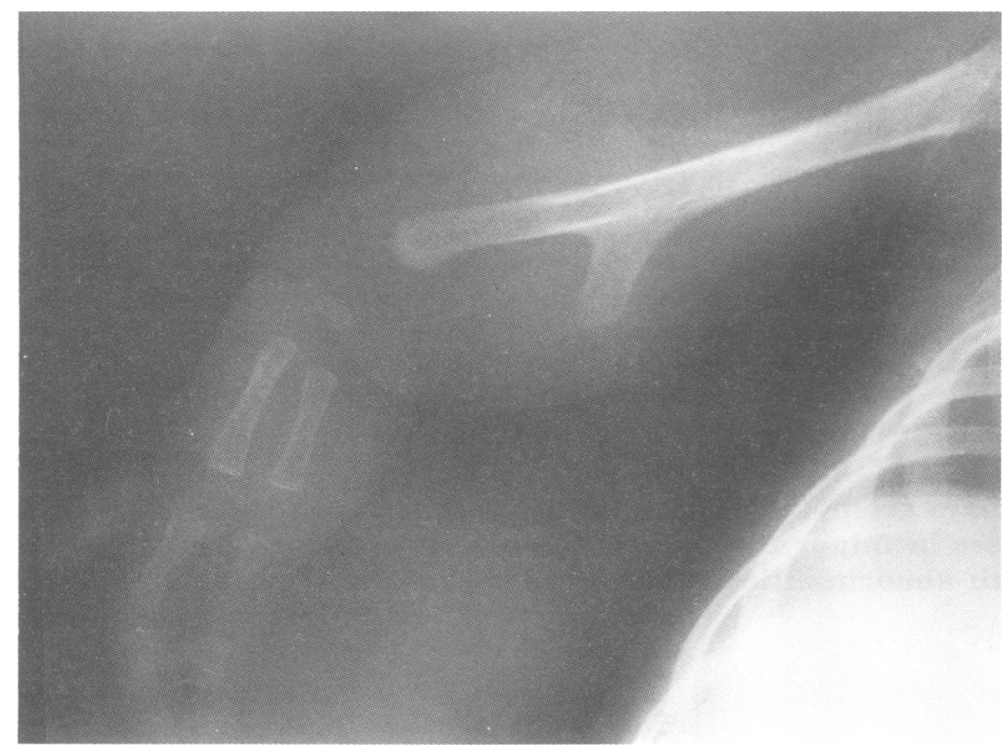

Figure 3 Radiograph of the right arm showing the bony abnormalities. similarity of the limb deformity in these four cases suggested that this case is more closely aligned to the humeroradioulnar synostosis group. The most intriguing factor of all four cases is the apparent bifurcation of the long bone of the arm. The pathogenesis of this is unclear.

This case therefore represents a variation of the three previously reported in that the upper limb defect is essentially unilateral and the plagiocephaly is represented by lambdoid synostosis. While this case broadens the spectrum of this entity it fails to shed any light on its aetiology.

1 Hersh JH, Joyce MR, Profumo LE. Humero-radio-ulnar synostosis: a new case and review. Am 7 Med Genet synostosis: a new case and review. Am f Med Genet

2 Leroy JG, Speeckaert MTC. Humero-radio-ulnar synostosis appearing as distal humeral bifurcation in a patient with distal phocomelia of the upper limb and radial ectrodactyly. Am F Med Genet 1984;18:365-8.

3 Gollop TR, Coates V. Apparent bifurcation of the distal humerus with oligoectrosyndactyly. Am $f$ Med Genet 1983;14:591-3 